\title{
Pharmacodynamics of CNTO 530 and Darbepoetin- $\alpha$ in Human TNF- $\alpha$ Transgenic Mice, a Murine Model of Anemia of Chronic Disease
}

\author{
Ram Achuthanandam ${ }^{1}$, Dorie Makropoulos ${ }^{1}$, Laura Johns ${ }^{1}$, Amy Volk ${ }^{1}$, Kerry Brosnan ${ }^{1}$, Jin Lu ${ }^{1}$, \\ Wojciech Krzyzanski ${ }^{2}$, Peter J. Bugelski ${ }^{1}$ \\ ${ }^{1}$ Centocor R\&D, Radnor, USA; ${ }^{2}$ Department of Pharmaceutics, State University of New York, Buffalo, USA. \\ Email: pbugelsk@its.jnj.com
}

Received October $22^{\text {nd }}, 2010$; revised November $16^{\text {th }}, 2010$; accepted December $13^{\text {th }}, 2010$.

\begin{abstract}
CNTO 530 and darbepoetin- $\alpha$ are long lived erythropoietin receptor agonists (ERAs). Clinically, anemia of chronic disease $(A C D)$ is associated with increased expression of tumor necrosis factor- $\alpha(T N F-\alpha)$ and mice transgenic for human TNF- $\alpha$ develop ACD. The purpose of this investigation was to compare the effects of these agents in a murine model of ACD. Human TNF- $\alpha$ expressing (Tg197) mice were administered a single subcutaneous dose of CNTO 530 or darbepoetin- $\alpha$ and the pharmacodynamic response in bone marrow spleen and peripheral blood evaluated. RBC life span and reticulocyte age distribution were also evaluated. CNTO 530 induced a dose responsive increase in reticulocytes, RBCs and Hgb in both wild type and Tg197 mice. Although the reticulocyte response was similar to wild types, the RBC and Hgb response to CNTO 530 in Tg197 mice was blunted. There was no statistically significant difference in RBC life span with either compound. Darbepoetin- $\alpha$ caused a greater peak in $\%$ dead Pro/basophilic erythroblasts, greater peak EMH in the spleen and a greater increase in reticulocyte maturation time. In contrast, despite a similar peak increase, CNTO 530 caused a more sustained response of reticulocyte, EMH, RBC and Hgb, consistent with increased exposure. In conclusion, CNTO 530 and darbepoetin- $\alpha$ increased RBC and hemoglobin in a murine model of $A C D$. Compared to darbepoetin- $\alpha, C N T O 530$ had a more sustained effect, consistent with increased exposure.
\end{abstract}

Keywords: Fusion Protein, Recombinant, Flow Cytometry, Erythropoiesis

\section{Introduction}

Anemia of chronic disease (ACD) is an important cause of co-morbidity in rheumatoid arthritis (RA), a systemic autoimmune disease afflicting $1-2 \%$ of the population $[1,2]$. Tumor necrosis factor- $\alpha(\mathrm{TNF}-\alpha)$ has been shown to play a central role in disease progression in RA (see review by Sfikakis and Kollias [3]) and has been implicated in the pathogenesis of ACD. In ACD patients there is increased local production of TNF- $\alpha$ in the bone marrow [4] and TNF- $\alpha$ is thought to contribute to ACD by decreasing red blood cell (RBC) survival, causing dysfunctional erythropoiesis and impairing mobilization of iron stores $[5,6]$.

Darbepoetin- $\alpha$ and CNTO 530 are long-lived erythropoietin receptor agonists. CNTO 530 is a $58 \mathrm{kD}$ glycoprotein MIMETIBODYTM construct that has been shown to cause a long-lived stimulation of erythropoiesis in mice and rats $[7,8]$. CNTO 530 has no sequence homology with erythropoietin (EPO). Rather, CNTO 530 includes two EMP1 sequences, a 20-amino acid peptide that binds to EPO receptors (EPO-R), on a human IgG4 Fc framework and expresses EPO-like bioactivity $[9,10]$ The purpose of this study was to determine if darbepoetin- $\alpha$ and CNTO 530 had beneficial effects in a murine model of ACD.

\section{Materials and Methods}

\subsection{Reagents and Monoclonal Antibodies}

Darbepoetin- $\alpha$ (Aranesp ${ }^{\circledR}$, Amgen, Inc. Thousand Oaks, CA) was purchased commercially and CNTO 530 was supplied by Centocor R \& D (Radnor, PA). Phosphate buffered saline (PBS) without $\mathrm{Ca}++$ and $\mathrm{Mg}++$, fetal calf serum (FCS), PE-anti-Ter-119, APC-streptavidin; PEstreptavidin; FITC-annexin V, isotype-matched IgG con- 
trols and the viability/DNA probe 7-amino-actinomycin D (7-AAD) were purchased from Invitrogen (Carlsbad, CA). EZ-Link NHS biotin was purchased from Pierce (Rockford, IL).

\subsection{Mice}

Heterozygous, 9 wk old Tg197 mice and CBA/C57Bl/6 F1 (CBA F1) control mice were supplied by Ace Laboratories (Boyertown, PA). Tg197 mice carry a human TNF- $\alpha / \beta$ globin transgene on a $\mathrm{C} 57 \mathrm{Bl} / 6$ background [11]. For these experiments, homozygous TNF- $\alpha$ transgenic males were bred to CBA females to provide heterozygous mice. All mice were maintained in the pathogenfree animal facility at Centocor, Radnor PA. The Centocor Institutional Animal Care and Use Committee approved all procedures.

\subsection{Hematology and Histology}

Blood was collected from mice anesthetized with a $\mathrm{CO} 2$ mixture via open chest cardiac puncture into EDTA coated microtubes. Analyses were performed on whole blood using an Advia 120 blood analyzer (Siemens, Tarrytown, NY). Spleens were collected, fixed in $10 \%$ neutral buffered formalin and processed for paraffin sections, sectioned and stained with Giemsa using routine methods. Extramedullary hematopoiesis (EMH) was evaluated morphometrically. Three $4 \mathrm{x}$ microscope fields from each mouse at each time point were digitally imaged. Polychromic/orthochromic erythroblasts (P/O EB) were identified by their size and staining characteristics and the percent area measured using ImagePro Plus $\mathrm{V}$ 5.1 (Media Cybernetics, Inc. Bethesda, MD). Mean values were calculated for each mouse. Data are shown as group mean \pm standard deviation.

\subsection{Bone Marrow Cell Preparation and Analysis}

Flow cytometric analysis was performed as described previously $[12,13]$. Briefly, femoral bone marrow was suspended in PBS without $\mathrm{Ca}++$ or $\mathrm{Mg}++$ supplemented with $2 \%$ heat-inactivated fetal calf serum (FCS) and $0.1 \% \mathrm{NaN}_{3}$. Following Fc block with anti-murine CD16/ CD32, cells were incubated with anti-Ter-119 and antiCD71 to discriminate erythroblasts from non-erythroid cells and pro/basophilic erythroblasts (Pro/BasoEB) from poly/orthochromic erythroblasts (Poly/OrthoEB). Apoptotic and dead cells were enumerated with annexin $\mathrm{V}$ and 7-aminoactinomycin-D (7AAD) as per manufacturer's instructions kit (BD Biosciences, San Jose, CA).

Samples were analyzed on a FACSCalibur flow cytometer (BD Biosciences, San Jose, CA). Data analysis was performed with CellQuest ProTM (BD Biosciences, San Jose, CA) and FlowJo (Treestar, Seattle, WA). Data for at least 10,000 cells/sample were collected. A nested analysis strategy was used to enumerate cell populations of interest: Debris and aggregates were excluded using FSC and SSC; apoptotoic (7AAD negative/annexin V+) and dead cells (7AAD+) and Pro/Basophilic (Pro/BasoEB, Ter119+/CD71 bright) and Poly/Orthochomic Erythroblasts (Poly/OrthoEB, Ter119+/CD71 dim) delimited using a Boolean "AND" operator.

\subsection{Pharmacokinetics}

Normal female C57B1/6 mice received a single sc dose of $0.3 \mathrm{mg} / \mathrm{kg}$ of CNTO 530 or darbepoetin- $\alpha$. Mice were euthanized (3-6 mice per time point) and blood samples collected by cardiac puncture into EDTA-coated microtubes. A total of 63 mice were used in this analysis. The plasma concentration of CNTO 530 was measured as described previously [12]. The plasma concentration of darbepoetin- $\alpha$ was measured in mouse plasma using a double-antibody sandwich ELISA (R\&D Systems, Inc., Minneapolis, MN) adapted for use with darbepoetin- $\alpha$ and murine plasma as described previously for recombinant human EPO [7].

\subsection{RBC Lifespan}

An in vivo biotinylation technique was used to determine RBC survival [14,15]. On Day 1, groups of Tg197 mice (5-6/group) received a single subcutaneous (sc) dose of saline, CNTO 530 or darbepoetin- $\alpha(0.3 \mathrm{mg} / \mathrm{kg})$. On Days 2, 3 and 4, the mice received EZ-Link Sulfo-NHS biotin ( $1 \mathrm{mg} / \mathrm{mouse}$, intravenous in $200 \mu \mathrm{L}$ PBS). Blood samples $(25 \mu \mathrm{L})$ were collected from the retro-orbital sinus (EDTA anticoagulant) on 1, 3, 6, 10, and 17 days after the last injection of biotin reagent. Blood $(5 \mu \mathrm{L})$ was mixed with $1 \mathrm{~mL}$ of $5 \mu \mathrm{g} / \mathrm{mL}$ of streptavidin-PE in PBS, and incubated for $30 \mathrm{~min}$. After a wash, the cells were resuspended in $200 \mathrm{uL}$ of PBS and analyzed by flow cytometry. Data for mean \% biotinylated $R B C$ was plotted as survival fraction vs. time. The initial slope $S_{0}$ of such a survival curve determines the mean $R B C$ lifespan $T_{R B C}$ according to the equation [16]:

$$
T_{R B C}=-\frac{1}{S_{0}}
$$

Although derived under homeostatic conditions, this relationship has been shown to be accurate for a nonstationary applications [17]. To determine the initial slope the $R B C$ survival curve for each animal was fitted with the liner-exponential model $[18,19]$ :

$$
S F(t)=\left\{\begin{array}{l}
\alpha S_{0}(t-T)+(\alpha-1) S_{0} / \lambda e^{-\lambda t}, \text { if } t<T, \\
(\alpha-1) S_{0} / \lambda e^{-\lambda t}, \text { if } t \geq T .
\end{array}\right.
$$


where $\lambda$ is the first-order rate constant of RBC random destruction, $T$ denotes the RBC lifespan due to senescence, and $0 \leq \alpha \leq 1$ is the weight factor between these two processes of the RBC removal. The parameters $T, \lambda$, and $S_{0}$ were estimated, and $S_{0}$ was calculated as follows:

$$
S_{0}=\frac{-1}{\alpha T+(1-\alpha) / \lambda}
$$

The nonlinear regression was performed by WinNonlin 5.0 (Pharsight, Mountain View, CA).

\subsection{Reticulocyte Age Distribution}

Oxazine 750 has been used as a marker of reticulocyte age. The fluorescent intensity signal $\mathrm{s}$ is correlated to the levels of $R N A$ present in the reticulocyte. If the reticulocyte $R N A$ degrades at a first-order rate, one can establish a relationship between the reticulocyte age and $s$, knowing that $s$ is proportional to the $R N A$ content [20]. To determine the absolute reticulocyte age, the signal from the bone marrow reticulocytes is necessary. Thus, the signal $s_{0}$ at which a reticulocyte becomes a mature $R B C$ has been used as a reference, and an absolute reticulocyte age/maturity has been replaced by a relative time to become $R B C(R T)$ according to the following equation:

$$
R T=\frac{t_{1 / 2 R N A}}{\ln 2} \ln \left(\frac{s}{s_{0}}\right)
$$

where $t_{1 / 2} R N A$ is the half-life of the $R N A$ degradation in reticulocytes. $R T$ densities were calculated at times $t=1$, $2,4,10$, and 21 days after test article administration. The $R T$ density $r(R T)$ function is defined as [20]:

$$
r(t, a)_{\Delta a}=\frac{\# \text { of reticulocytes of } R T(a, a+\Delta a)}{\text { Unit Volume of blood }}
$$

where, $\Delta a$ is an infinitesimally small age increment. The $R T$ densities were approximated by the product of absolute reticulocyte count at time $t$ and the frequency histogram for $R T$ at time $t$ :

$$
r(t, R T)=\frac{R E T(t) * \operatorname{hist}(t, R T)}{\Delta R T}
$$

where, $\Delta R T$ is the length of the histogram bin. The production rate of mature $R B C$ at time $\mathrm{t}$ was calculated as:

$$
k_{R E T}(t)=\max _{0 \leq R T} r(t, R T)
$$

and the maximal value of the $R T$ density was used to approximate the reticulocyte release rate from the bone marrow to blood:

$$
k_{R E T}(t)=\max _{0 \leq R T} r(t, R T)
$$

The mean $R T$ was calculated from the histogram hist $(t$, $R T)$. The median of $r(R T)$ was interpreted as the median cell age (mid age of reticulocytes). Since the half-life of the RNA degradation in Tg197 transgenic mice has not been determined, $R T$ was expressed in $t_{1 / 2} R N A$ units. The ADVIA 120 FCS files were converted to ASCII files containing reticulocyte oxazine 750 absorption intensity data using FCS Express v. 3 (De Novo Software). The RT densities, and other reticulocyte related parameters were obtained using MATLAB 7.6 (MathWorks, Natick, MA).

\subsection{Statistical Analysis}

Data were expressed as means $+/-$ standard deviation. Significant differences between experimental groups were determined by ANOVA (Bonferroni's correction). $P$ values less than 0.05 were considered significant.

\section{Results}

\subsection{Dose Response of CNTO 530 in Tg197 Mice}

As shown in Table 1, Tg197 mice have a mild compensated, hypochromic aqnemia. To establish the dose response for CNTO 530, female $\operatorname{Tg} 197$ mice (4/group) received a single subcutaneous (sc) dose of CNTO 530 at $0.03,0.1$ or $0.3 \mathrm{mg} / \mathrm{kg}$. Control $\mathrm{Tg} 197$ mice received a single sc dose of PBS. As shown in Figures 1(a)-(c), CNTO 530 caused a dose responsive increase in reticulocytes, RBC and Hgb in Tg197 mice. Based on these results, a dose of $0.3 \mathrm{mg} / \mathrm{kg}$ was chosen for the remaining experiments.

\subsection{Comparative Effects of CNTO 530 in Normal and Tg197 Mice}

To compare the response of normal (CBF1) and Tg197 mice to CNTO 530, 9 week-old female mice (3/group) received a single sc dose of $0.3 \mathrm{mg} / \mathrm{kg}$. Control mice received a single sc dose of PBS. As shown in Figure 2(a), the reticulocyte response to CNTO 530 in CBF1 and

Table 1. Combined control values for normal and Tg197 mice.

\begin{tabular}{lcc}
\hline \multicolumn{1}{c}{ Parameter } & CBF1 & Tg197 \\
\hline Reticulocytes & $210 \pm 27$ & $256 \pm 65^{*}$ \\
Total RBC & $9.7 \pm 0.3$ & $9.6 \pm 0.7$ \\
$\mathrm{MCV}$ & $54.2 \pm 0.5$ & $53.1 \pm 1.8$ \\
$\mathrm{MCH}$ & $16.4 \pm 0.7$ & $15.5 \pm 0.9^{*}$ \\
$\mathrm{Hgb}$ & $15.8 \pm 0.4$ & $14.8 \pm 0.9^{*}$ \\
\hline
\end{tabular}

*Significantly different from CBF1 (t-test). 


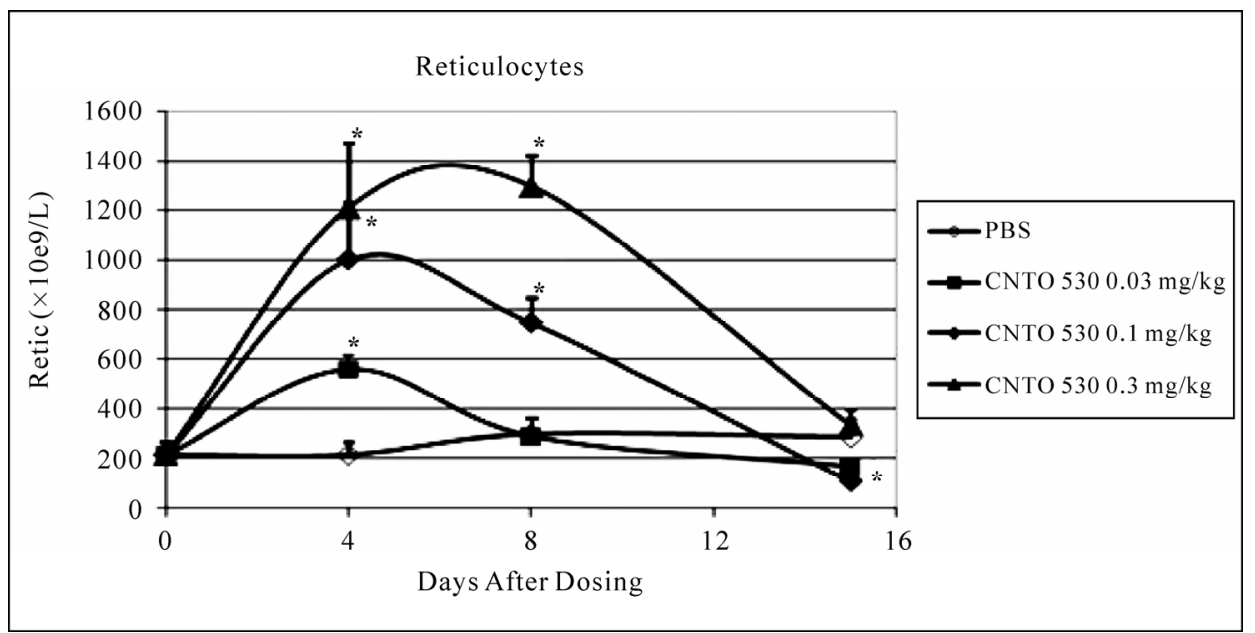

(a)

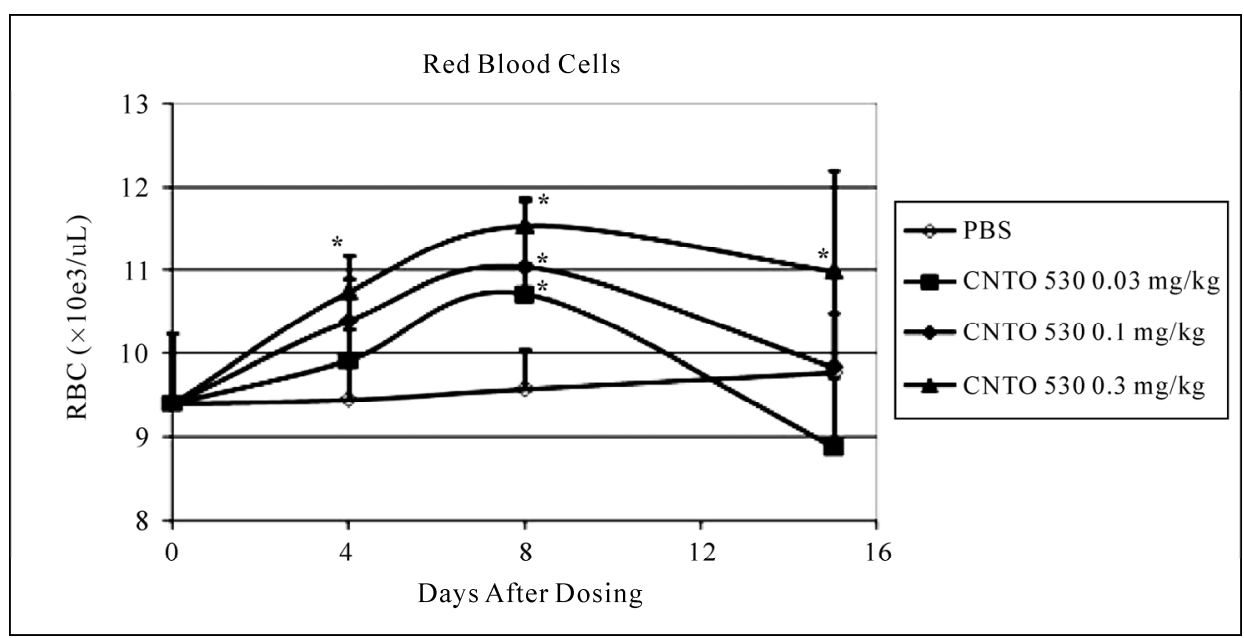

(b)

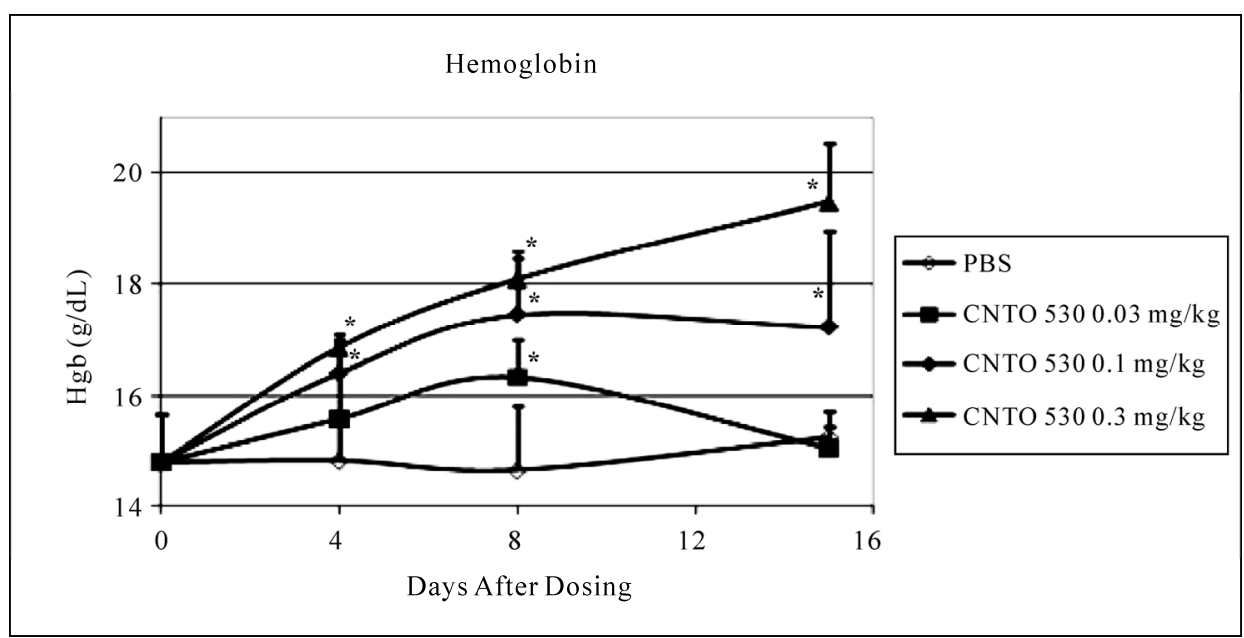

(c)

Figure 1. Dose response for CNTO 530 in Tg197 mice. (a), (b) and (c) show reticulocyte, RBC and HgB responses to CNTO 530 as a function of time. *statistically significant difference from control. 
Pharmacodynamics of CNTO 530 and Darbepoetin- $\alpha$ in Human TNF- $\alpha$ Transgenic Mice, a Murine Model of Anemia of Chronic Disease

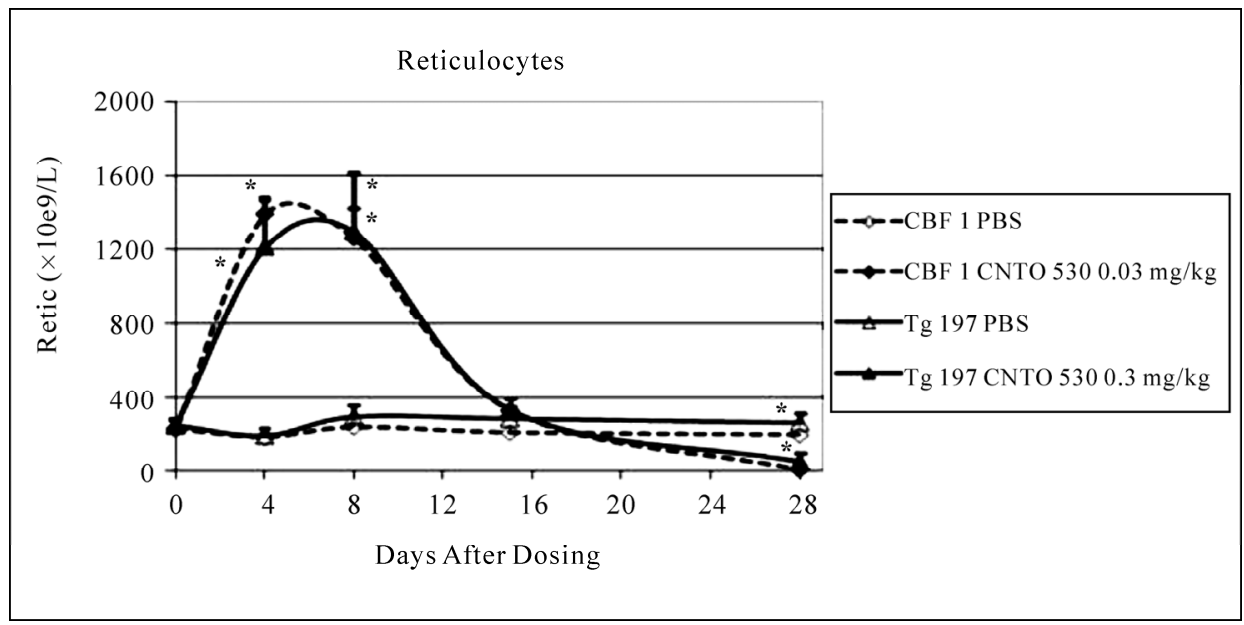

(a)

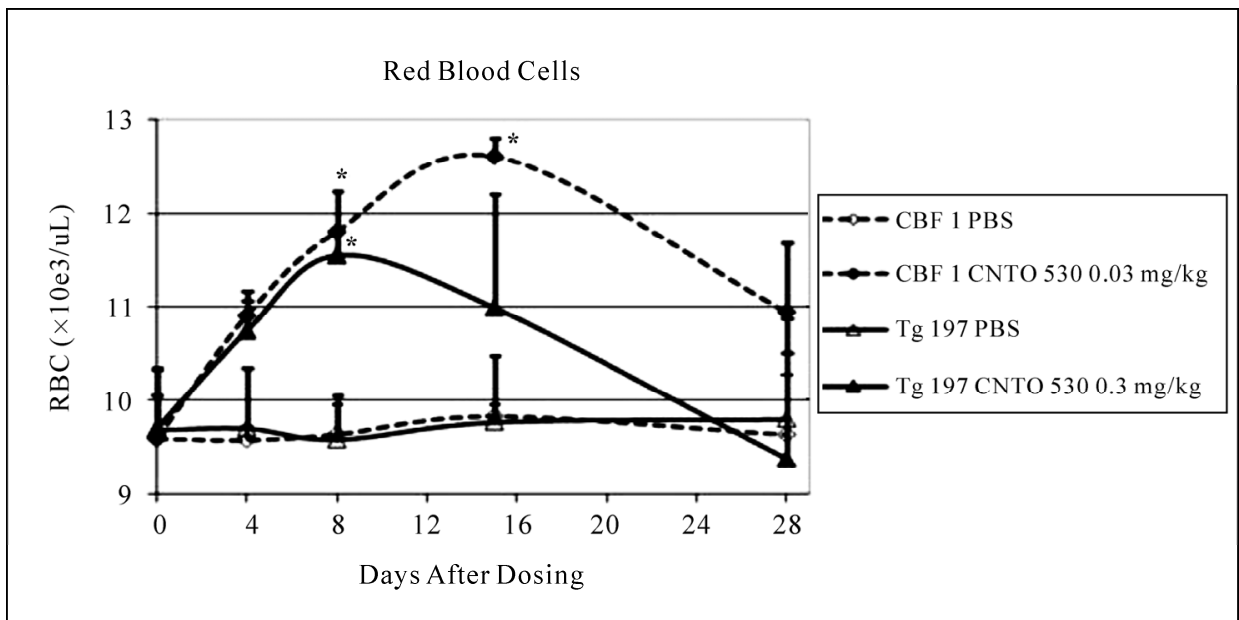

(b)

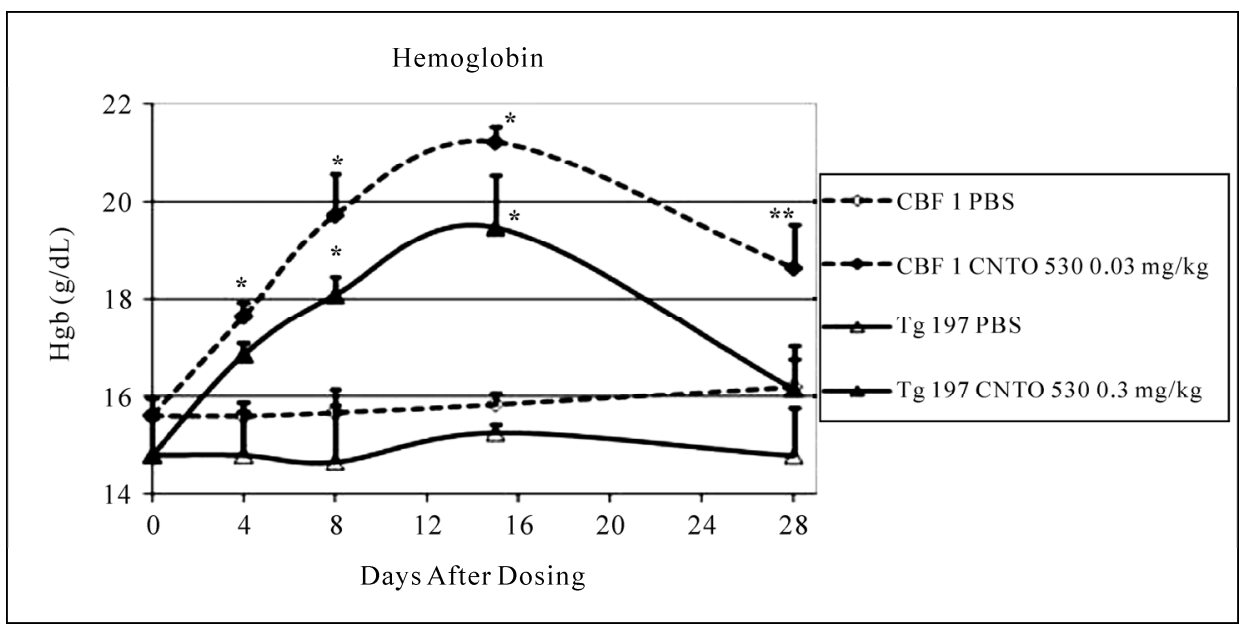

(c)

Figure 2. Comparative pharmacodynamics of CNTO 530 in normal CBF1 and Tg197 mice. (a) reticulocyte response. (b) RBC response. (c) Hgb response. *statistically significant difference from untreated control. **statistically significant difference from Tg197 mice. 
Tg197 mice was similar. However, as shown in Figures 2(b) and 2(c), the RBC and Hgb response was attenuated, suggesting that Tg197 mice are resistant to CNTO 530.

\subsection{Comparative Pharmacokinetics of CNTO 530 and Darbepoetin- $\alpha$}

Female $\mathrm{C} 57 \mathrm{Bl} / 6$ mice (5-6/group) received a single sc dose of CNTO 530 or darbepoetin- $\alpha(0.3 \mathrm{mg} / \mathrm{kg})$ and blood samples collected from $2 \mathrm{hrs}$ to 10 days after dosing. Plasma concentrations are shown in Figure 3 and the pharmacokinetic parameters in Table 2. Compared to darbepoetin- $\alpha$, there was a statistically significant increase in the area under the curve (AUC) and terminal half-life for CNTO 530.

\subsection{Pharmacodynamics of CNTO 530 and Darbepoetin- $\alpha$ in Tg197 Mice}

Female Tg197 mice (4/group) received a single sc dose of CNTO 530 or darbepoetin- $\alpha(0.3 \mathrm{mg} / \mathrm{kg})$ and blood, bone marrow and spleens were collected 1,2, 4, 10 and

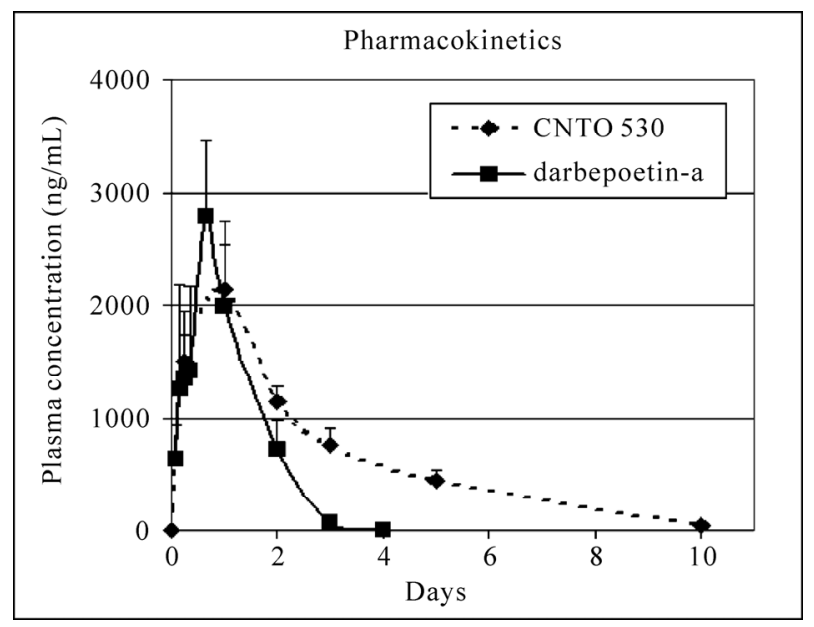

Figure 3. Comparative pharmacokinetics of CNTO 530 and darbepoetin- $\alpha$ in normal mice.

Table 2. Pharmacokinetics of CNTO 530 and darbepoetin- $\alpha$ following a single subcutaneous dose in mice.

\begin{tabular}{|c|c|c|}
\hline Parameter & $\begin{array}{c}\text { CNTO 530 } \\
(\text { mean } \pm \text { SD })\end{array}$ & $\begin{array}{c}\text { Darbepoetin- } \alpha \\
(\text { mean } \pm \text { SD) }\end{array}$ \\
\hline Cmax (ug/mL) & $2.2 \pm 0.5$ & $2.9 \pm 0.5$ \\
\hline Tmax (hr) & $20 \pm 8$ & $19 \pm 5$ \\
\hline $\mathrm{AUC}_{\mathrm{t}}(\mathrm{ug} \cdot \mathrm{hr} / \mathrm{mL})$ & $152 \pm 28 *$ & $80 \pm 10$ \\
\hline AUC (ug.hr/mL) & $160 \pm 20 *$ & $95 \pm 11$ \\
\hline $\mathrm{t}_{1 / 2}(\mathrm{hr})$ & $41 \pm 9^{*}$ & $14 \pm 4$ \\
\hline
\end{tabular}

*Statistically greater than darbepoetin- $\alpha$.
21 days after dosing. Controls received a single sc dose of PBS. As shown in Figure 4(a), CNTO 530 and darbepoetin- $\alpha$ caused a similar peak reticulocyte response. However, the reticulocyte response to CNTO 530 was longer-lived. CNTO 530 and darbepoetin- $\alpha$ also caused an increase in RBC (Figure 4(b)) and Hgb (Figure 4(c)). Despite a similar peak effect on RBC and Hgb, the effects on CNTO 530 were significantly longer-lived than the effects of darbepoetin- $\alpha$.

Representative scatter plots showing CD71 vs. Ter119 and annexin-V vs. 7-AAD for bone marrow from Tg197 mice are shown in Figures 5(a) and (b). As shown in Figure 5(c), with both test articles the relative percentages of Pro/BasoEB initially fell and then recovered to control values by Day 10 and then again fell below control values on Day 21. Similarly, Poly/OrthoEB percentages also initially fell below control values and then recovered for darbepoetin- $\alpha$ or rose above control values for CNTO 530 by Day 10 (Figure 5(d)). Poly/OrthoEB were elevated for both test articles on Day 21. The results of the analysis of apoptosis and cell death in the bone marrow are shown in Figures 5(e) and (f). Both test articles transiently increased cell death in Pro/BasoEB. In contrast, neither test article had a significant effect on apoptosis of Pro/BasoEB until Day 21 when apoptosis was decreased. Neither test article had an effect on apoptosis or cell death in Poly/OrthoEB at any time point evaluated (Data not shown).

In the spleen, animals treated with CNTO 530 or darbepoetin- $\alpha$ showed an expansion of extramedullary hematopoiesis (EMH) (Figure 6). On Day 1, erythroid precursors were the predominant cell types and were found in clusters in the red pulp. In these clusters, some cells could be identified as Pro/BasoEB, however many cells appeared to be more primitive, with large pale nuclei that contained multiple nucleoli. This early progenitor population was the predominant cell type in roughly half of the animals. By Day 2, the primitive population and the Pro/BasoEB had expanded to a high degree and mitotic figures could be observed in the early progenitors. By Day 4, EMH peaked in both groups of treated animals. At this time, there was a shift from the primitive cells toward Pro/BasoEB. Additionally, the number of Poly/ OrthoEB and mature RBC had expanded to nearly the degree of the earlier precursors. There also was also an increase in apoptotic bodies in both groups of treated animals compared with control animals. Although the effects of CNTO 530 and darbepoetin- $\alpha$ were similar on Days 1 and 2, by Day 4 the degree of EMH was greater in animals treated with darbepoetin- $\alpha$ relative to those treated with CNTO 530. By Day 10, there was a striking difference between CNTO 530 and darbepoetin- $\alpha$-treated 
Pharmacodynamics of CNTO 530 and Darbepoetin- $\alpha$ in Human TNF- $\alpha$ Transgenic Mice, a Murine Model of Anemia of Chronic Disease

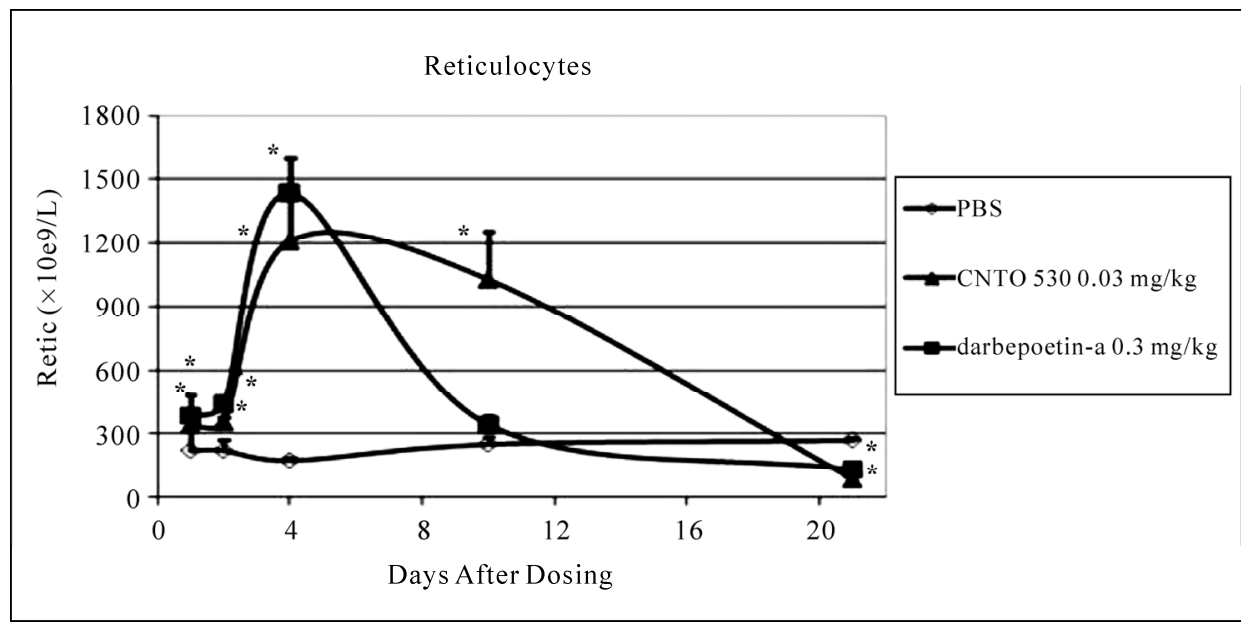

(a)

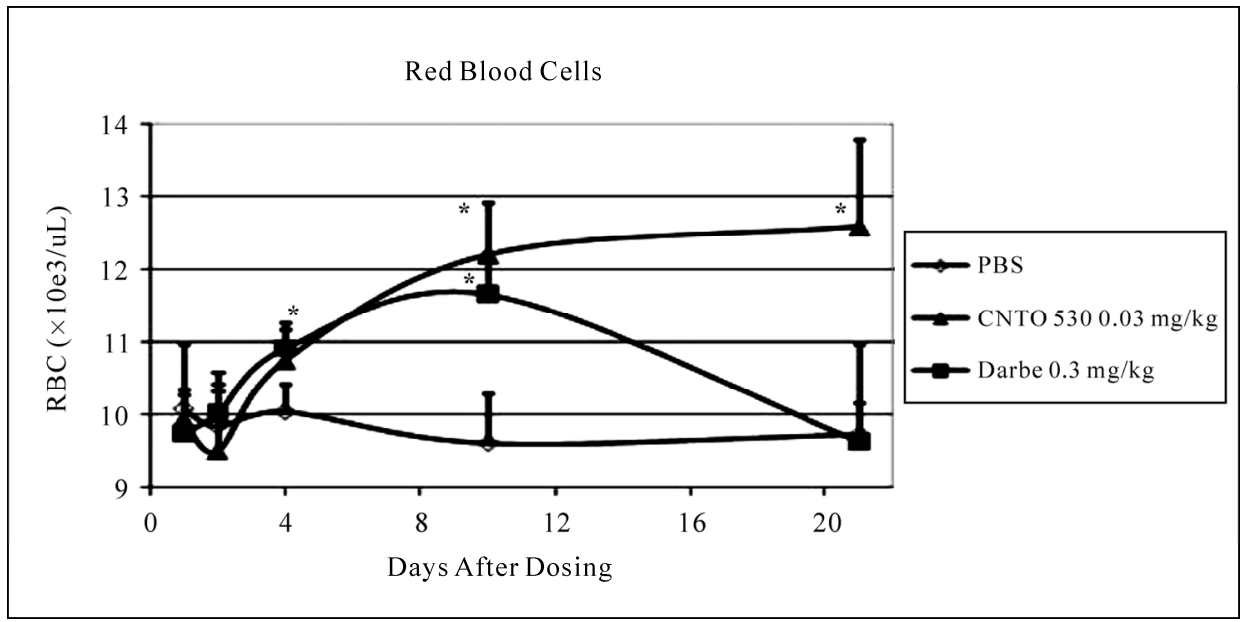

(b)

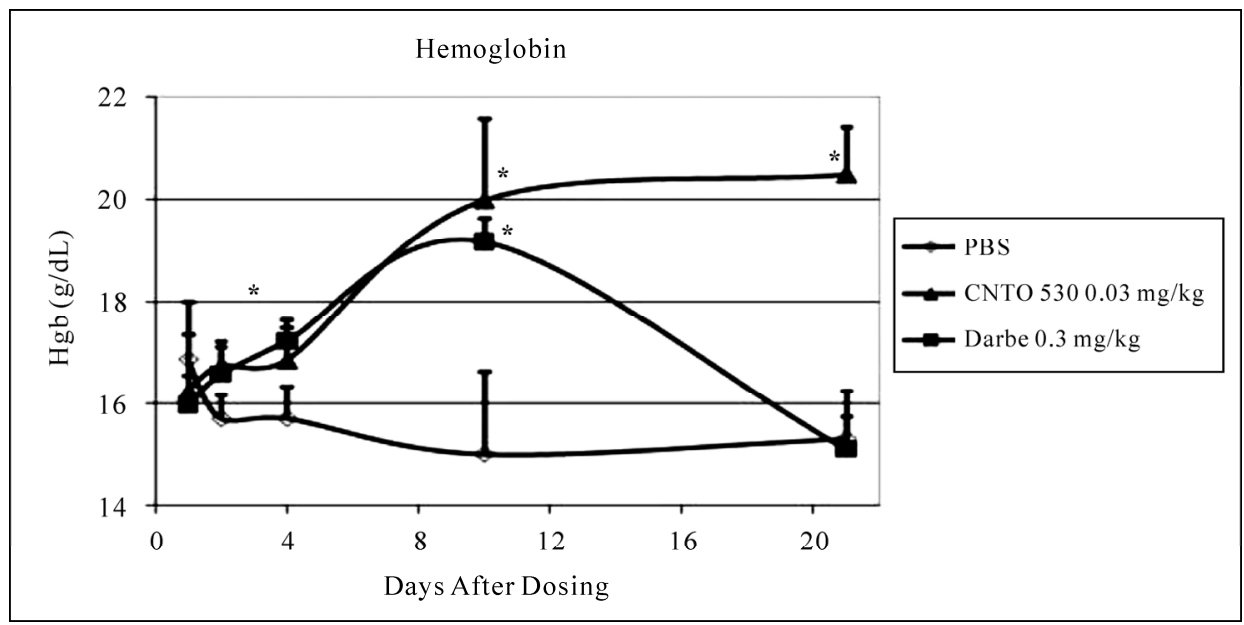

(c)

Figure 4. Comparative pharmacodynamics of CNTO 530 and darbepoetin in Tg197 mice. (a), (b) and (c) show reticulocyte, RBC and HgB responses to CNTO 530 as a function of time. *statistically significant difference from untreated control. $* *$ significantly different from control and darbepoetin- $\alpha$. 


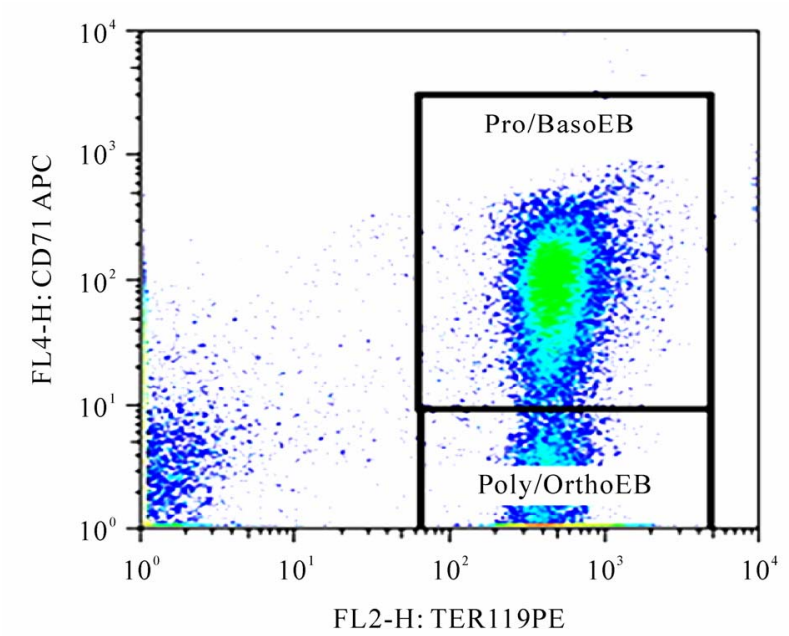

(a)

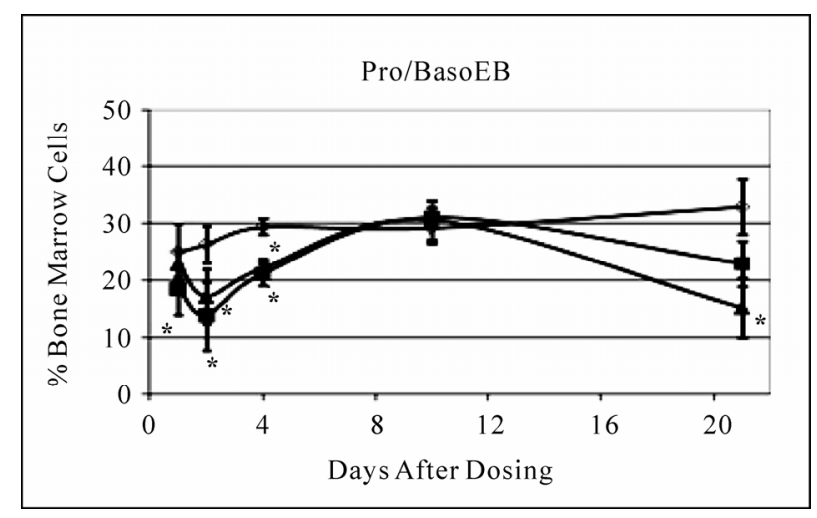

(c)

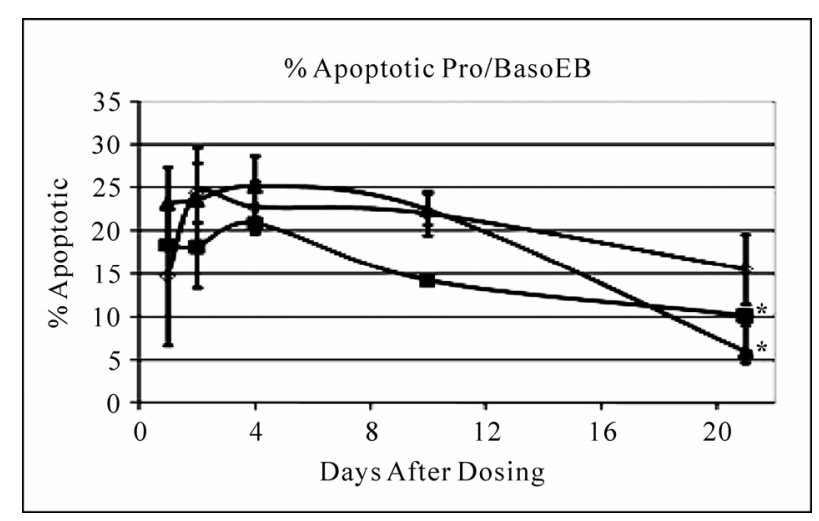

(e)

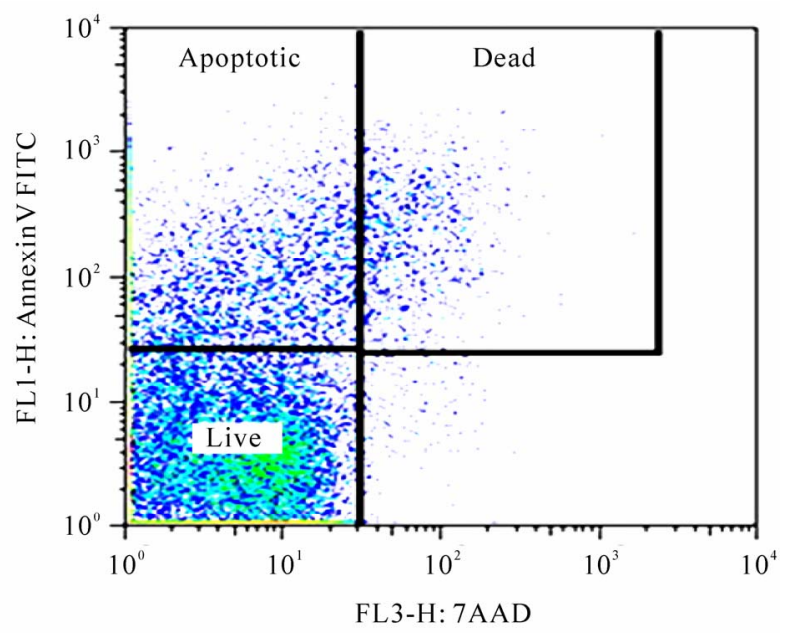

(b)

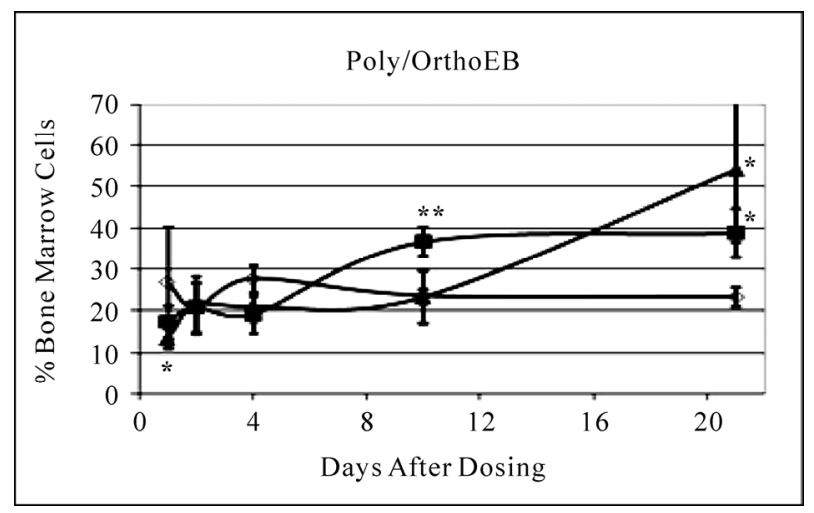

(d)

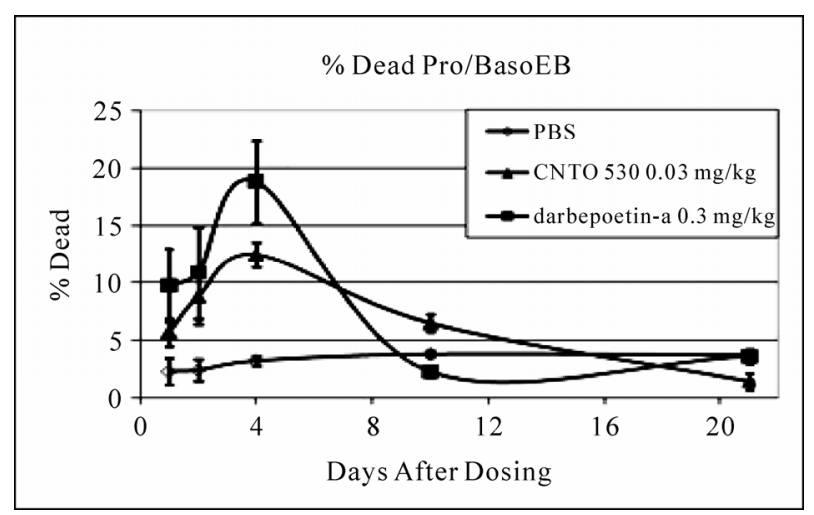

(f)

Figure 5. Comparative effects of CNTO 530 and darbepoetin- $\alpha$ in the bone marrow of Tg197 mice. (a) representative scatter plot showing flow cytometric discrimination of erythroid precursors. Proerythroblasts and basophilic erythroblasts (Pro/BasoEB) are identified as Ter119 high/CD71+. Polychromic and orthochromic erythroblasts (Poly/OrthoEB) are identified as Ter199 hi/CD71-. (b) representative scatter plot showing flow cytometric discrimination of live, apoptotic and dead erythroid precursors. Live cells are identified as AnnexinV-/7AAD-, apoptotic cells as AnnexinV+/7AAD- and dead cells as 7AAD+. (c) comparative pharmacodynamic effect of CNTO 530 and darbepoetin- $\alpha$ on Pro/BasoEB. (d) comparative pharmacodynamic effect of CNTO 530 and darbepoetin- $\alpha$ on Poly/OrthoEB. (e) and (f) comparative pharmacodynamic effects on $\%$ apoptotic and \% dead Pro/BasoEB. *statistically significant difference from untreated control. **significantly different from control and darbepoetin- $\alpha$. 


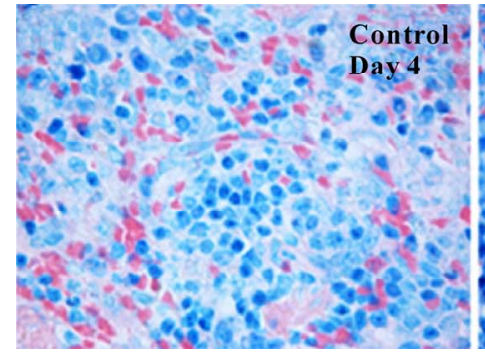

(a)

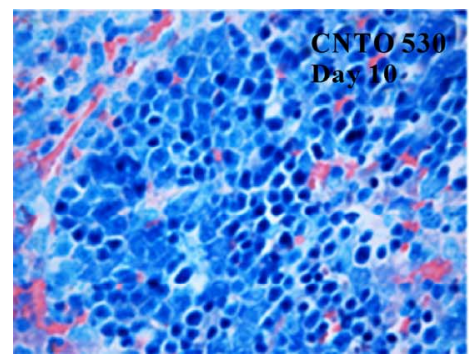

(d)

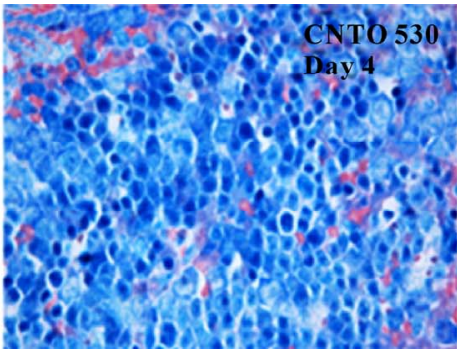

(b)

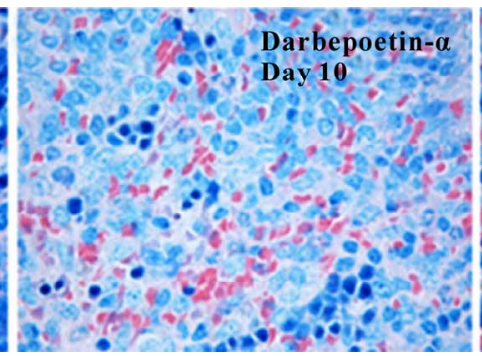

(e)

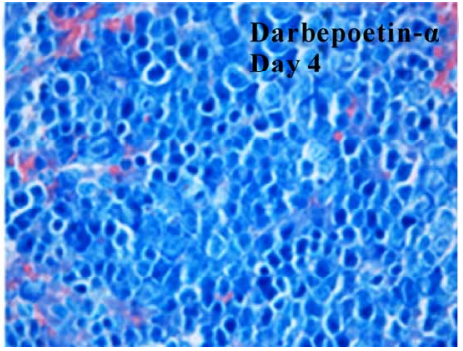

(c)

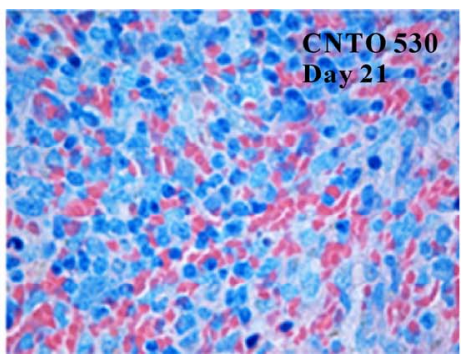

(f)

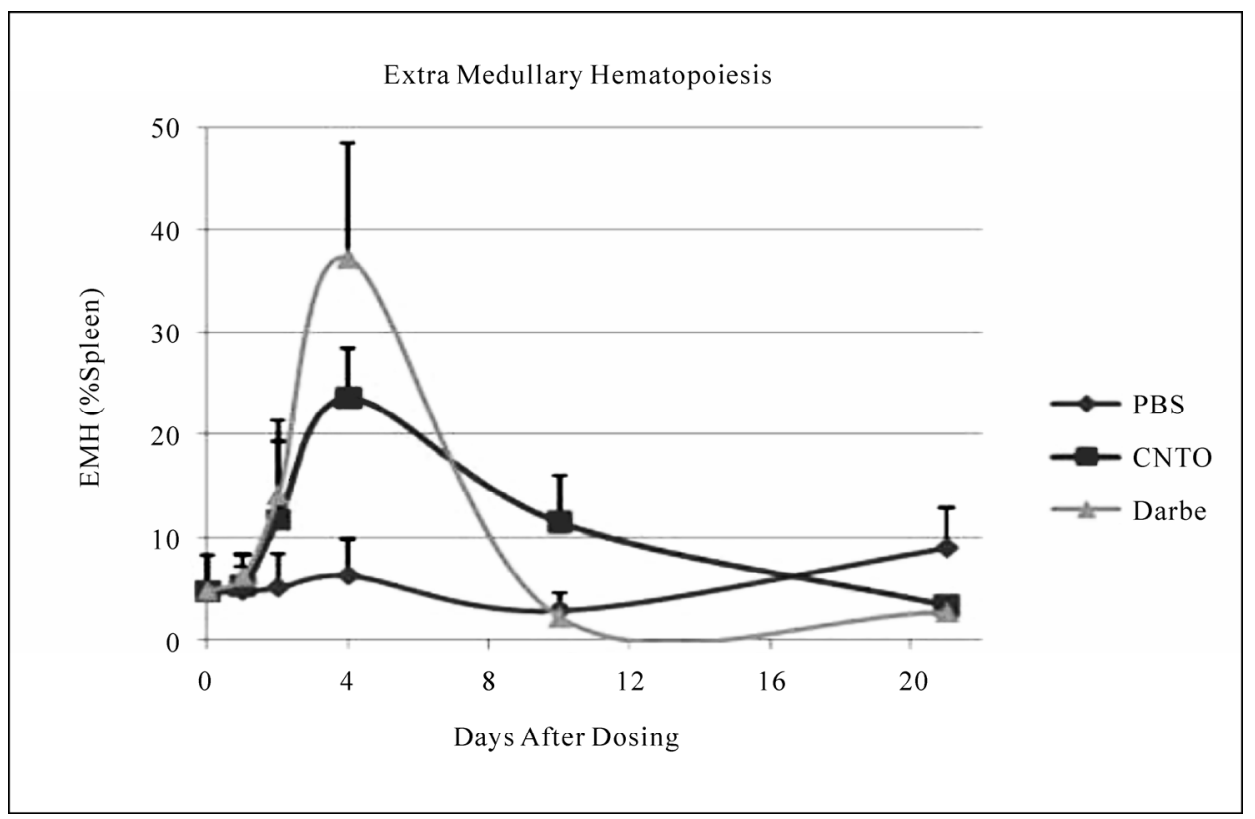

(g)

Figure 6. Comparative pharmacodynamic effects of CNTO 530 and darbepoetin- $\alpha$ on extramedullary erythropoiesis (EMH). Photomicrographs of the red pulp of formalin fixed, paraffin embedded, Giemsa stained sections of the spleen from Tg197 mice. (a) control Day 4, (b) CNTO 530 Day 4, (c) darbepoetin- $\alpha$ Day 4, (d) CNTO 530 Day 10, (e) darbepoetin- $\alpha$ Day 10 and (f) CNTO 530 Day 21. Basophilic erythroblasts are recognized as the large deeply blue stained nuclei. Bar $=100 \mu \mathrm{m}$. $(\mathrm{g})$ morphometric analysis of EMH. CNTO 530 caused a longer-lived increase in expansion of P/OEB in the spleen.

animals. While there remained significant EMH in animals treated with CNTO 530, EMH was reduced in the darbepoetin- $\alpha$ group. In the CNTO 530 treated animals, early stage progenitors were still present, however the overall EMH had shifted to later stage Poly/OrthoEB and there were widespread areas of mature RBCs. Scattered apoptotic bodies could be observed in this group. In the darbepoetin- $\alpha$-treated animals, the progenitor population was mixed, with sporadic progenitors at varying stages present at low frequency and there were abundant mature 
RBC. By Day 21, the control animals were also showing moderate EMH, probably reflecting a response to disease progression. At this time, there were no notable differences between the CNTO 530 and darbepoetin- $\alpha$ treated animals.

In peripheral blood, increases in reticulocytes are observed by Day 1 for both compounds, and by Day 4 there is a $\sim 6$ fold increase in circulating reticulocytes. After Day 4, the levels of reticulocytes reflect the pharmacokinetic properties of each of the molecules as shown in Figure 4. The increase in reticulocytes is followed by a delayed increase in RBCs observed at Day 4. Again, the $\mathrm{RBC}$ profiles reflect the pharmacokinetic properties with increased RBC levels observed up till Day 21 in CNTO 530 treated group.

\subsection{Effects of CNTO 530 and Darbepoetin- $\alpha$ on RBC Life Span}

As shown in Figure 7(g), the surviving fraction of RBC was significantly lower than control for both treatment groups on Day 1 and significantly higher than control for the CNTO 530 group on Day 17. There was no statistically significant effect of either test article on mean RBC lifespan: control $=22 \pm 6$ days; CNTO 530 $=24 \pm 2$ days and darbepoetin- $\alpha=19 \pm 1$ days.

\subsection{Effects of CNTO 530 and Darbepoetin- $\alpha$ on Reticulocyte and RBC Production Rates and Reticulocyte Age Distribution}

The reticulocyte rates of release to the blood are presented in Figure 7(d). For treated mice $k_{R E T}$ gradually increased up to Day 2, to rapidly increase within the next two days, and reached a peak on Day 4. Following the peak, the production rates declined to reach the values below the control group on Day 21. The $k_{R E T}$ for mice that received PBS was at the same level of about $0.34 \pm$ $0.0810^{12} \mathrm{cell} / \mathrm{s} / \mathrm{L} / \mathrm{t}_{1 / 2 \mathrm{RNA}}$. Darbepoetin- $\alpha$ increased $k_{R E T}$ higher than CNTO $530(2.07 \pm 0.16$ vs. $1.71 \pm 0.36$ $10^{12}$ cells/ $\left./ \mathrm{L} / \mathrm{t}_{1 / 2 \mathrm{RNA}}\right)$ but the difference was not statistically significant. This effect of CNTO 530 on $k_{R E T}$ lasted longer than darbepoetin- $\alpha$. Both darbepoetin- $\alpha$ and CNTO 530 resulted in $k_{R E T}$ values that were significantly less than the control group $(0.21 \pm 0.04$ and $0.16 \pm 0.05$ $10^{12} \mathrm{cells} / \mathrm{L} / \mathrm{t}_{1 / 2 \mathrm{RNA}}$, respectively) at Day 21 .

The time courses of the mean time for reticulocyte to become mature RBC $(R T)$ for the three groups of mice are shown in Figure 7(e). For control mice, the mean $R T(m R T)$ values remained at the same level of $4 t_{1 / 2 R N A}$. The $m R T$ values for both CNTO 530 and darbepoetin- $\alpha$ groups reached the peaks of $7.4 \pm 0.6 t_{1 / 2 R N A}$ and $9.3 \pm 0.9$ $t_{1 / 2 R N A}$, respectively, on Day 2 which were significantly different. The time courses of the $m R T$ following the peak were different for two groups. The RT values for mice treated with darbepoetin- $\alpha$ declined more rapidly and reach a nadir of $2.9 \pm 0.6 t_{1 / 2 R N A}$ on Day 10 and reached a plateau at this value, whereas the mean for the CNTO 530 group gradually declined to reach $3.5 \pm 0.4$ $t_{1 / 2 R N A}$ on Day 21. The $m R T$ on Day 21 for both treatment groups was significantly smaller than the $m R T$ value for the control group.

The mature RBC production rate vs. time plot is shown in Figure 7(f). The $k_{R B C}$ values for the PBS group were relatively constant $0.16 \pm 0.0310^{12} \mathrm{cells} / \mathrm{L} / t_{1 / 2 R N A}$. The time courses of $k_{R B C}$ for treated animals exhibited a 2 day lag prior to a rapid increase followed by a gradual decline. The peak of $0.46 \pm 0.0810^{12}$ cells $/ \mathrm{L} / t_{1 / 2 R N A}$ for the darbepoetin- $\alpha$ group occurred on Day 4 whereas the peak of $0.46 \pm 0.0410^{12} \mathrm{cells} / \mathrm{L} / t_{1 / 2 R N A}$ for the CNTO 530 group was on Day 10 . The peak values were not significantly different. This effect of CNTO 530 on $k_{R B C}$ lasted longer than darbepoetin- $\alpha$. The $k_{R B C}$ values on Day 21 for the treated animals were significantly lower than for the PBS group.

\section{Discussion}

In our studies in huTNF- $\alpha$ transgenic mice, it was observed that CNTO 530 and darbepoetin- $\alpha$ caused a dose responsive stimulus of erythropoiesis. Moreover, CNTO 530 had a superior pharmacokinetic and pharmacodynamic profile compared to darbepoetin- $\alpha$ in this model where the mice were relatively resistant to CNTO 530 (blunted response) compared to normal mice at the same dose level.

The model of ACD used in these experiments, $\operatorname{Tg} 197$ mice, are transgenic for human TNF- $\alpha$ and develop a progressive polyarthritis starting at 4-5 weeks of age [1]. Arthritis is well established by 10 weeks of age and anemia is correlated with disease progression and huTNF- $\alpha$ concentrations in the serum, despite the presence of adequate iron stores in the spleen and normal levels of endogenous erythropoietin [2]. That TNF- $\alpha$ can induce anemia in mice has been reported previously. Single intraperitoneal doses of murine TNF- $\alpha$ have been reported to cause a decrease in hematocrit [3] and transplantation of $\mathrm{CHO}$ cells transfected with a human TNF- $\alpha$ gene caused anemia within 3 weeks [4]. Similarly, mice transgenic for human TNF- $\alpha$ developed a microcytic anemia at 16 weeks of age [5].

When compared to normal mice, $\operatorname{Tg} 197$ mice were relatively resistant to CNTO 530. In contrast to our previous results in normal mice where a single sc dose of epoetin- $\alpha$ or CNTO 530 caused an expansion of Pro/ BasoEB in bone marrow [6,7], in $\operatorname{Tg} 197$ mice CNTO 530 and darbepoetin- $\alpha$ caused a decrease in Pro/BasoEB. As 


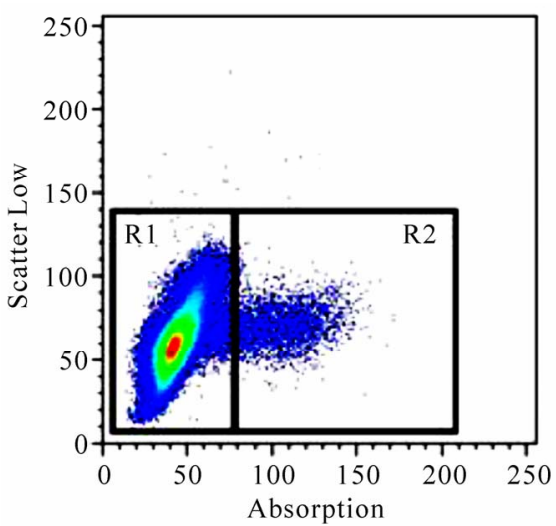

(a)

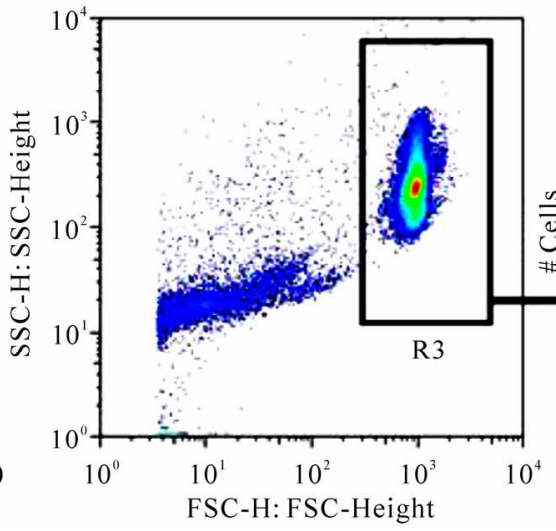

(b)

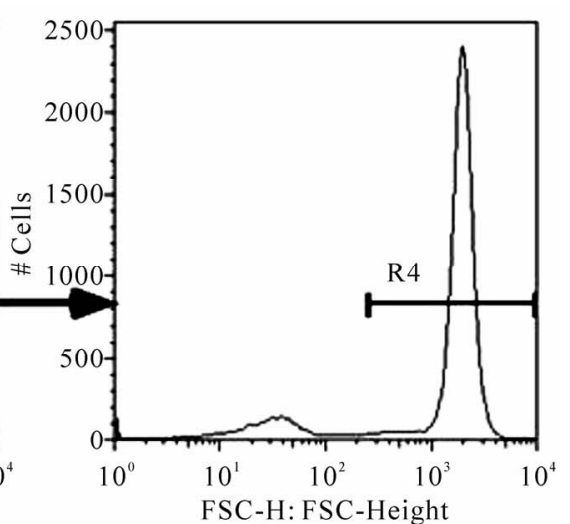

(c)

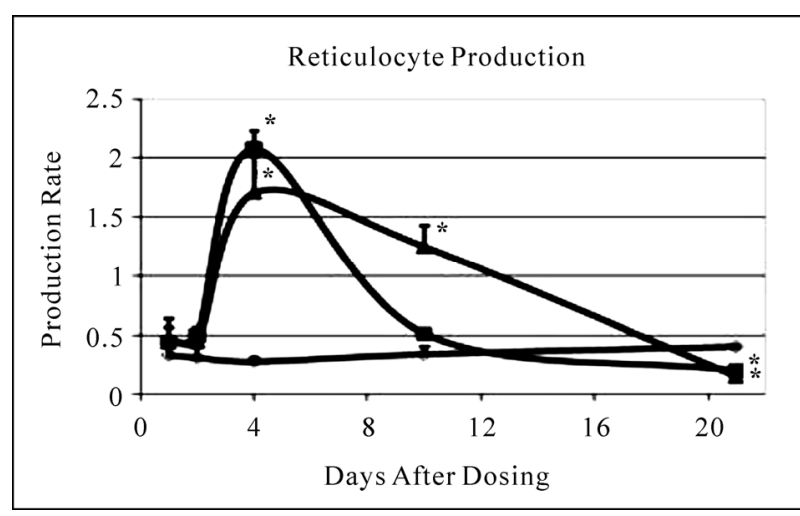

(d)

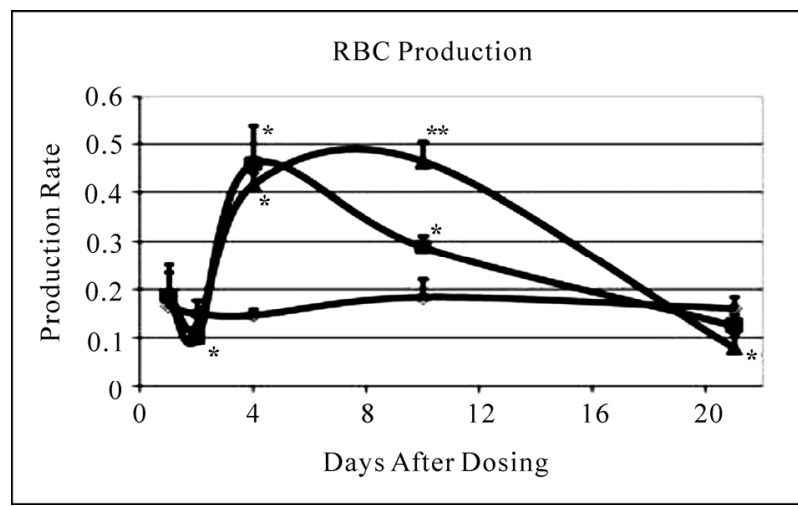

(f)

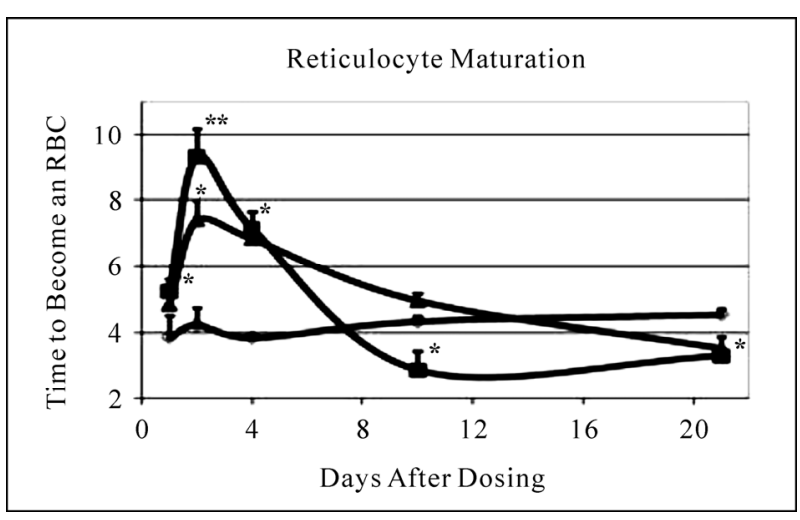

(e)

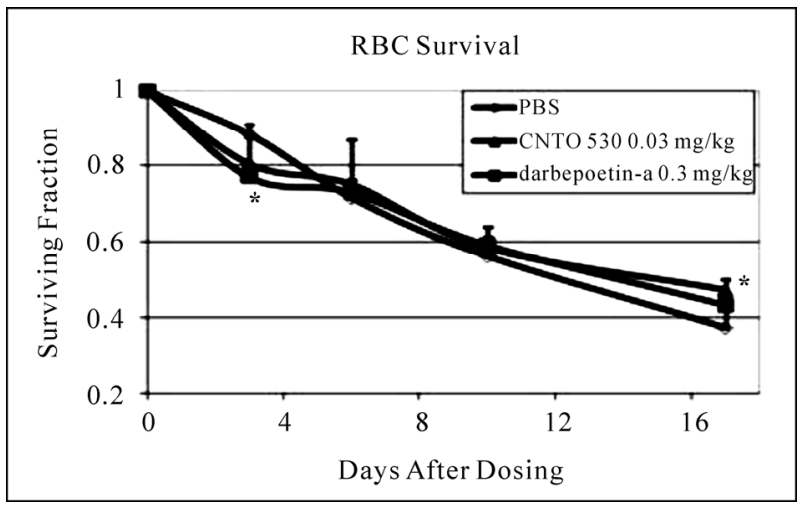

(g)

Figure 7. Comparative effects of CNTO 530 and darbepoetin- $\alpha$ on reticulocyte and RBC dynamics. (a) representative scatter plot showing flow cytometric discrimination of recticulocytes, and its age distribution. Data are taken from the Advia 120 from Day 10 and show oxizine staining (absorption) plotted against forward scatter. Gate R1 + R2 represents total RBCs + Reticulocytes with $\mathrm{R} 2$ showing the age of reticulocytes. (b)-(c) representative scatter plot showing flow cytometric discrimination of biotinylated RBC. 7(b) shows the delineation of RBCs (R3) and (R4) showing the percentage of RBCs that are biotinylated. On Day 1, mice received a single sc dose of saline, CNTO 530 or darbepoetin- $\alpha(0.3 \mathrm{mg} / \mathrm{kg})$. On Days 2 , 3 and 4 , the mice received EZ-Link Sulfo-NHS biotin. (d) production rate of reticulocytes (RT). The rate of production was calculated as described in Materials and Methods (Units $=1012$ Cells/L/t1/2RNA). (e) reticulocyte maturation (kRET). The time to for a reticulocyte to mature into an $\mathrm{RBC}$ was calculated as described in Materials and Methods (Units $=$ t1/2RNA). (f) production rate of RBC (RT). The rate of production was calculated as describe in Materials and Methods (Units $=1012 \mathrm{Cells} / \mathrm{L} / \mathrm{t} 1 / 2 \mathrm{RNA})$. (g) surviving fraction of RBC (RBC SF) was calculated as describe in Materials and Methods (Units = \% biotinylated RBC). *statistically significant difference from untreated control. **significantly different from control and darbepoetin- $\alpha$. 
reported previously, a single intraperitoneal dose of murine TNF- $\alpha$ caused a decrease in the number of colony forming units in the spleen and bone marrow in mice [3]. Similarly, in human ACD there is a decrease in the number of erythroblasts and increased apoptosis in the bone marrow [8] and a relative resistance to EPO [9]. As the murine p75 TNF-receptor is selective for murine TNF- $\alpha$ and fails to mediate signaling from human TNF- $\alpha$ [10], resistance to CNTO 530 may be mediated through the p55 TNF-receptor.

Previously, darbepoetin- $\alpha$ has been shown to be active in a model of ACD in rats [11]. In our study, we have found that compared to darbepoetin- $\alpha$, CNTO 530 has a superior pharmacodynamic effect on $\mathrm{RBC}$ and $\mathrm{Hgb}$ in a murine model of ACD. In an attempt to elucidate the mechanism of the pharmacodynamics we have evaluated the effects of CNTO 530 and darbepoetin- $\alpha$ on the bone marrow, EMH, reticulocyte production and maturation and RBC life span. The superior pharmacodynamic effects of CNTO 530 are unlikely to be due to differential effects on the bone marrow. Neither test article caused an expansion of medullary hematopoiesis. Similarly, both test articles caused an increase in cell death in Pro/BasoEB that followed a roughly similar time course. Moreover, neither test article had an effect on apoptosis in Pro/BasoEB nor an effect on apoptosis/cell death in Poly/ OrthoEB. Apoptosis and cell death have been shown previously to play a critical role in controlling erythropoiesis and it is well established that deprivation of EPO-R stimulation leads to apoptosis of erythroid precursors [12, 13] However, as we have reported previously in normal mice [6,7], a single sc dose of epoetin- $\alpha$ or CNTO 530 caused an increase in cell death in erythroblasts. Similarly, Chang et al. [14] reported increased apoptosis/cell death in erythroblasts in mice receiving three doses of recombinant murine EPO. Increased apoptosis/cell death was also reported by Robinson et al. [15] in erythroblasts in mice following hemorrhagic shock, despite a strong endogenous EPO response. Taken together, these findings suggest that apoptosis and cell death play a role in erythroid homeostasis when EPO-R mediated stimulation of erythropoiesis is either high or low.

Our data also suggest that the superior pharmacodynamics of CNTO 530 cannot be attributed to a differential effect on EMH. Both test articles caused an expansion of EMH, albeit with somewhat different kinetics. Repeated dosing with epoetin- $\alpha$ has been shown to increase EMH in mice and rats $[16,17]$ Similarly, Kapa et al. [18] found that the response to exogenous EPO after hypoxia was more pronounced in the spleen than in the bone marrow. This is consistent with the expansion of EMH in mice receiving either CNTO 530 or darbepo- etin- $\alpha$ and suggests that in $\operatorname{Tg} 197$ mice as has been described previously in normal mice [17], the spleen provides a better microenvironment for EPO mediated expansion of erythropoiesis than the bone marrow.

Both darbepoetin- $\alpha$ and CNTO 530 affected reticulocyte maturation and $\mathrm{RBC}$ production profiles. Though, there was not a statistically significant difference in the number of reticulocytes in the periphery at Day 1 and 2, a difference in reticulocyte maturation was observed at these time points. Both test articles induced release of immature reticulocytes into the periphery, without changing the reticulocyte production. Moreover, a decrease in $\mathrm{RBC}$ production rate is concomitantly observed with the increase in immature reticulocytes. This suggests that not only are immature reticulocytes released into the periphery, but both compounds delay the maturation of the reticulocytes to RBCs. However, the compounds did not affect the RBC life span with treatment, making it unclear how the delayed maturation process of reticulocytes aided in production of better RBCs.

When we compare the two erythropoietin receptor agonists, they have similar mode of action in this model of ACD. Having ruled out fundamentally different effects on most aspects of erythropoiesis, we are left with differences in the duration of the stimulation of erythropoiesis between the two compounds. Pharmacokinetic analysis showed that the terminal $t_{1 / 2}$ and AUC for CNTO 530 was significantly greater than darbepoetin- $\alpha$, resulting in a longer duration of exposure to CNTO 530. This longer duration of exposure was reflected in the prolonged increase in $R T, k_{R E T}, k_{R B C}$ and reticulocytosis seen with CNTO 530 and suggests that the differential effects of CNTO 530 and darbepoetin- $\alpha$ on RBC and $\mathrm{Hgb}$ may simply reflect longer lasting effects on the final stages of erythropoiesis.

\section{Acknowledgements}

The authors thank Renold Capocasale for generating the flow cytometry data. All authors (except WK) are employees of Centocor R\&D. CNTO 530 was discovered by Centocor R\&D.

\section{REFERENCES}

[1] G. S. Alarcon, "Epidemiology of Rheumatoid Arthritis," Rheumatologic Disease Clinics of North America, Vol. 21, No. 3, 1995, pp. 589-604.

[2] K. C. Das and M. A. Sattar, "Serum and Red Cell Ferritin Content in the Evaluation of Iron Status in Rheumatoid Arthritis," Scandinavian Journal of Rheumatology, Vol. 18, 1989, pp. 399-405. doi:10.3109/03009748909102102

[3] P. P. Sfikakis and G. Kollias, "Tumor Necrosis Factor Biology in Experimental and Clinical Arthritis," Current 
Opinion in Rheumatology, Vol. 2003, No. 15, 2005, pp. 380-386.

[4] M. Jongen-Lavrencic, H. R. Peeters, A. Wognum, G. Vreugdenhil, F. C. Breedveld and A. J. Swaak, "Elevated Levels of Inflammatory Cytokines in Bone Marrow of Patients with Rheumatoid Arthritis and Anemia of Chronic Disease," Journal of Rheumatology, Vol. 24, No. 8, 1997, pp. 1504-1509.

[5] R. T. Means, Jr., "Recent Developments in the Anemia of Chronic Disease," Current Hematology Reports, Vol. 2, No. 2, 2003, pp. 116-121.

[6] L. L. Moldawer, M. A. Marano, H. Wei, et al., "Cachectin/Tumor Necrosis Factor-Alpha Alters Red Blood Cell Kinetics and Induces Anemia in vivo," FASEB Journal, Vol. 3, No. 5, 1989, pp.1637-1643.

[7] P. J. Bugelski, T. Nesspor, A. Volk, et al., "Pharmacodynamics of Recombinant Human Erythropoietin in Murine Bone Marrow," Pharmaceutics Research, Vol. 25, No. 2, 2008, pp. 369-378. doi:10.1007/s11095-007-9372-7

[8] P. Sathyanarayana, E. Houde, D. Marshall, et al., "CNTO 530 Functions as a Potent EPO Mimetic via Unique Sustained Effects on Bone Marrow Proerythroblast Pools," Blood, Vol. 113, No. 20, 2009, pp. 4955-4962. doi:10.1182/blood-2008-08-172320

[9] D. L. Johnson, F. X. Farrell, F. P. Barbone, et al., "Identification of a 13 Amino Acid Peptide Mimetic of Erythropoietin and Description of Amino Acids Critical for the Mimetic Activity of EMP1," Biochemistry, Vol. 37, No. 11, 1998, pp. 3699-3710. doi:10.1021/bi971956y

[10] O. Livnah, D. L. Johnson, E. A. Stura, et al., "An Antagonist Peptide-EPO Receptor Complex Suggests that Receptor Dimerization is not Sufficient for Activation," Nature Structural Biology, Vol. 5, No. 11, 1998, pp. 9931004. doi:10.1038/2965

[11] J. Keffer, L. Probert, H. Cazlaris, et al., "Transgenic Mice Expressing Human Tumour Necrosis Factor: A Predictive Genetic Model of Arthritis," EMBO Journal, Vol. 10, No. 13, 1991, pp. 4025-4031.

[12] P. J. Bugelski, R. J. Capocasale, D. Makropoulos, et al., "CNTO 530: Molecular Pharmacology in Human UT7EPO Cells and Pharmacokinetics and Pharmacodynamics in Mice," Journal of Biotechnology, Vol. 134, No. 1-2, 2008, pp. 171-180. doi:10.1016/i.jbiotec.2007.12.005.

[13] R. Achuthanandam, J. Quinn, R. J. Capocasale, P. J. Bugelski, L. Hrebien and M. Kam, "Sequential Univariate Gating Approach to Study the Effects of Erythropoietin in Murine Bone Marrow," Cytometry A, Vol. 73, No. 8, 2008, pp. 702-714. doi:10.1002/cyto.a.20584

[14] G. Hoffmann-Fezer, C. Trastl, W. Beisker, et al. "Preclinical Evaluation of Biotin Labeling for Red Cell Survival Testing," Annals of Hematology, Vol. 74, No. 5, 1997, pp. 231-238. doi:10.1007/s002770050290

[15] T. Suzuki and G. L. Dale, "Biotinylated Erythrocytes: In Vivo Survival and In Vitro Recovery," Blood, Vol. 70, No. 3, 1987, pp. 791-795.
[16] A. C. Dornhorst, "The Interpretation of Red Cell Survival Curves," Blood, Vol. 6, No. 12, 1951, pp. 1284-1292.

[17] H. Breny, "Non-Stationary Models," In: J. M. Paulus, Ed., Platelet Kinetics: Radioisotopic, Cytological, Mathematical and Clinical Aspects, North-Holland, Amsterdam, The Netherlands, 1971.

[18] D. M. Mock, G. L. Lankford, J. A. Widness, L. F. Burmeister, D. Kahn and R. G. Strauss, "Measurement of Red Cell Survival Using Biotin-Labeled Red Cells: Validation Against 51Cr-Labeled Red Cells," Transfusion, Vol. 39, No. 2, 1999, pp. 156-162. doi:10.1046/j.1537-2995.1999.39299154729.x

[19] M. Kotilainen, "Linear and Exponential Components of Platelet Turnover: A Computer Analysis," In: J. M. Paulus, Ed., Platelet Kinetics: Radioisotopic, Cytological, Mathematical and Clinical Aspects, North-Holland, Amsterdam, The Netherlands, 1971.

[20] P. Wiczling and W. Krzyzanski, "Flow Cytometric Assessment of Homeostatic Aging of Reticulocytes in Rats," Experimental Hematology, Vol. 36, No. 2, 2008, pp. 119-127. doi:10.1016/j.exphem.2007.09.002

[21] R. J. Capocasale, D. A. Makropoulos, R. Achuthanandam, et al., "Myelodysplasia and Anemia of Chronic Disease in Human Tumor Necrosis Factor-Alpha Transgenic Mice," Cytometry A, Vol. 73, No. 2, 2008, pp. 148-159. doi:10.1002/cyto.a.20512

[22] C. S. Johnson, C. A. Cook and P. Furmanski, "In vivo Suppression of Erythropoiesis by Tumor Necrosis Factor-Alpha (TNF-alpha): Reversal with Exogenous Erythropoietin (EPO)," Experimental Hematology, Vol. 18, No. 2, 1990, pp. 109-113.

[23] R. A. Johnson, T. A. Waddelow, J. Caro, A. Oliff and G. D. Roodman, "Chronic Exposure to Tumor Necrosis Factor in vivo Preferentially Inhibits Erythropoiesis in Nude Mice," Blood, Vol. 74, No. 1, 1989, pp. 130-138.

[24] H. Glosli, O. P. Veiby, H. Fjerdingstad, et al., "Effects of hTNFalpha Expression in T Cells on Haematopoiesis in Transgenic Mice," European Journal of Haematology, Vol. 63, No. 1, 1999, pp. 50-60. doi:10.1111/j.1600-0609.1999.tb01850.x

[25] H. A. Papadaki, H. D. Kritikos, V. Valatas, D. T. Boumpas and G. D. Eliopoulos, "Anemia of Chronic Disease in Rheumatoid Arthritis is Associated with Increased Apoptosis of Bone Marrow Erythroid Cells: Improvement Following Anti-Tumor Necrosis Factor-Alpha Antibody Therapy," Blood, Vol. 100, No. 2, 2002, pp. 474-482. doi:10.1182/blood-2002-01-0136

[26] G. Vreugdenhil, A. W. Wognum, H. G. van Eijk and A. J. Swaak, "Anaemia in Rheumatoid Arthritis: The Role of Iron, Vitamin B12, and Folic Acid Deficiency, and Erythropoietin Responsiveness," Annals of Rheumatic Disease, Vol. 49, No. 2, 1990, pp. 93-98. doi:10.1136/ard.49.2.93

[27] M. Lewis, L. A. Tartaglia, A. Lee, et al., "Cloning and Expression of cDNAs for Two Distinct Murine Tumor Necrosis Factor Receptors Demonstrate One Receptor is 
Species Specific," Proceeding of the National Academy of Science (USA), Vol. 88, No. 7, 1991, pp. 2830-2834. doi:10.1073/pnas.88.7.2830

[28] M. A. Coccia, K. Cooke, G. Stoney, et al., "Novel Erythropoiesis Stimulating Protein (Darbepoetin Alfa) Alleviates Anemia Associated with Chronic Inflammatory Disease in a Rodent Model," Experimental Hematology, Vol. 29, No. 10, 2001, pp. 1201-1209. doi:10.1016/S0301-472X(01)00723-8

[29] U. Testa, "Apoptotic Mechanisms in the Control of Erythropoiesis," Leukemia, Vol. 18, No. 7, 2004, 11761199. doi:10.1038/sj.leu.2403383

[30] M. J. Weiss and C. O. dos Santos, "Chaperoning Erythropoiesis," Blood, Vol. 113, No. 10, 2009, pp. 2136-2144. doi:10.1182/blood-2008-09-115238

[31] K. H. Chang, M. Tam and M. M. Stevenson, "Inappropriately Low Reticulocytosis in Severe Malarial Anemia Correlates with Suppression in the Development of Late Erythroid Precursors," Blood, Vol. 103, No. 10, 2004, pp. 3727-3735. doi:10.1182/blood-2003-08-2887
[32] Y. Robinson, A. Matenov, S. K. Tschoke, et al., "Impaired Erythropoiesis after Haemorrhagic Shock in Mice is Associated with Erythroid Progenitor Apoptosis in vivo," Acta Anaesthesiologica Scandinavia, Vol. 52, No. 5, 2008, pp. 605-613. doi:10.1111/j.1399-6576.2008.01656.X

[33] M. Kato, Y. Kato and Y. Sugiyama, "Mechanism of the Upregulation of Erythropoietin-Induced Uptake Clearance by the Spleen," American Journal of Physiology, Vol. 276, No. 5, 1999, pp. E887-E895.

[34] W. Nijhof, H. Goris, B, Dontje, J. Dresz and M. Loeffler, "Optimal Erythroid Cell Production during Erythropoietin Treatment of Mice Occurs by Exploiting the Splenic Microenvironment," Experimental Hematology, Vol. 21, No. 4, 1993, pp. 496-501.

[35] D. Kapa, L. Biljanovic-Paunovic, P. Milenkovic and V. Pavlovic-Kentera, "Effect of Suppression and Stimulation of Erythropoiesis on CFU-E in Mouse Spleen," Acta Haematologica, Vol. 72, No. 5, 1984, pp. 295-302. doi:10.1159/000206405 